Marquette University

e-Publications@Marquette

Psychology Faculty Research and Publications

Psychology, Department of

$10-1-2013$

\title{
Acculturative Stress and Latino Depression: The Mediating Role of Behavioral and Cognitive Resources
}

Mark W. Driscoll

Marquette University

Lucas Torres

Marquette University, lucas.torres@marquette.edu

Accepted version. Cultural Diversity and Ethnic Minority Psychology, Vol. 19, No. 4 (October 2013): 373-382. DOI. (C) 2013 American Psychological Association. Used with permission.

This article may not exactly replicate the final version published in the APA journal. It is not the copy of record. 


\title{
Acculturative Stress and Latino Depression: The Mediating Role of Behavioral and Cognitive Resources
}

\author{
Mark W. Driscoll \\ Psychology Department, Marquette University \\ Milwaukee, WI \\ Lucas Torres \\ Psychology Department, Marquette University \\ Milwaukee, WI
}

\begin{abstract}
Although research has found that acculturative stress is significantly associated with adverse psychological adjustment among Latinos, the mechanism by which this relationship exists is not clearly understood. The purpose of this study was to investigate the role of behavioral and cognitive resources - active coping and self-efficacy, respectively - as mediators of the relationship between acculturative stress and depression among a sample of Latina/o adults $(N=469)$. Multiple mediator analysis indicated active coping partially mediated the relationship between acculturative stress and depression symptom severity. The indirect relationship of acculturative stress to depression symptom severity through self-efficacy was not significant. The results suggest that acculturative stress directly relates to Latino psychological adjustment, and lower behavioral active coping partially accounts for this relationship. Results are discussed in the context of
\end{abstract}


NOT THE PUBLISHED VERSION; this is the author's final, peer-reviewed manuscript. The published version may be accessed by following the link in the citation at the bottom of the page.

culturally-based stress and coping models, wherein the relationship between stressors and subsequent psychological adjustment is influenced by the degree of fit between stressor demands and individuals' resources. Implications for treatment and theory are discussed.

Keywords: Latinos, depression, acculturative stress, active coping, selfefficacy

Latinos comprise a significant and growing segment of the changing demography of the United States. The 2010 American Community Survey (ACS) estimated that Latinos comprised $16.4 \%$ of the total United States population (Pew Hispanic Center, 2012). This proportion increased from $12.5 \%$ of the total population in 2000 and, relative to other ethnocultural groups, constituted the greatest overall change in representation during the 2000-2010 period. However, despite increased national representation and visibility, research continues to show evidence of substantial disparities in the psychological functioning of Latinos living in the United States. For example, Latinos have been found to score higher than non-Latino whites on continuous measures of depression symptom severity (Mendelson, Rehkopf, \& Kubzansky, 2008). Furthermore, U.S.-born Latinos evince worse psychological adjustment relative to immigrant Latinos (Alegría, Canino, Shrout, Woo, Duan, Vila et al., 2008), and psychological functioning is worse among Latinos who immigrated to the United States prior to the start of adolescence or after 35 years of age (Alegría, Mulvaney-Day, Torres, Polo, Cao, \& Canino, 2007). Latinos are also disproportionately exposed to social contexts (e.g., discrimination, development of bicultural identity, geographic separation from family) that adversely influence psychological functioning. For example, findings from the National Latino and Asian American Study (NLAAS) indicate that approximately $30 \%$ of Latinos reported experiencing moderate to high levels of discrimination (Pérez, Fortuna, \& Alegría, 2008). Although exposure to these social contexts may directly influence Latino psychological adjustment, research suggests that these social contexts also shape Latino mental health outcomes through their adverse influence on the psychosocial correlates of cultural change and adaptation (Dawson \& Panchanadeswaran, 2010; Torres, Driscoll, \& Voell, 2012). In particular, the resultant stress associated with the experience of cultural adaptation and adjustment, or acculturative stress, has been American Psychological Association and permission has been granted for this version to appear in e- 
implicated as an important process that significantly influences Latinos' psychological functioning.

Within this context, stress and coping frameworks have played a central role in clarifying potential mechanisms that link culturallybased stress and psychological adjustment (Lazarus \& Folkman, 1984; Chun, Moos, \& Cronkite, 2006). Previous research has examined single coping processes using simple mediation analysis (e.g., Torres, 2009), or has investigated the degree to which particular coping strategies moderated the influence of acculturative stress on Latino psychological functioning (e.g., Crockett, Iturbide, Torres Stone, McGinley, Rafaelli, \& Carlo, 2007). Thus, prior research has not yet been able to compare the concurrent influence of multiple individual resources on psychological adjustment, nor evaluate potential mechanisms by which acculturative stress is associated with variability in Latino mental health outcomes. This study aimed to address these gaps in the research literature by comparing the relative influence of behavioral and cognitive resources as variables that confer the indirect influence of acculturative stress on Latino depression. Specifically, the roles of problem-focused, planful coping styles that focus on mastery and behavioral competency, or active coping (Zea, Reisen, \& Tyler, 1996), and cognitive beliefs in one's ability to effectively cope with challenges and stressors, or self-efficacy (Bandura, 1977; Bandura, 2001), were examined as types of behavioral and cognitive resources, respectively, using a multiple mediator analytic technique (Preacher \& Hayes, 2008).

Acculturative stress refers to stress reactions experienced by individuals during the processes of cultural adaptation and adjustment (Berry, 2006; Umaña-Taylor \& Alfaro, 2009). Initial conceptualizations of acculturative stress focused on the acquisition of culturally-based behavioral and cognitive skill sets not associated with an individual's culture of origin, specifically when expressed cultural behaviors constitute a poor "fit" with the social environment in which an individual is embedded. Acculturative stress may be experienced, for example, as a result of acquiring the ability to speak or understand English, or through the adoption of mainstream American values such as individualism. This definition emphasizes the degree to which acculturating individuals demonstrate deficits in behaviors typically associated with the mainstream culture as the principal sources of 
acculturative stress. More recent conceptualizations of acculturative stress, however, emphasize potential conflicts stemming from progressive acquisition of characteristics associated with the majority culture as well as from lower retention of behaviors and practices associated with one's Latino cultural background (Rodriguez, Myers, Mira, Flores, \& Garcia-Hernandez, 2002). Acculturative stress may thus correspond to tensions from maintaining continuity with the behaviors and characteristics of one's heritage culture while concurrently adopting behaviors and characteristics associated with the majority culture, or from the loss of cultural behaviors and characteristics associated one's Latino background (e.g., through family intergenerational conflict; Castillo, Cano, Chen, Blucker, \& Olds, 2008). Therefore, as has been argued by other researchers, acculturative stress is not an experience unique to immigrant Latinos (Castillo et al., 2008; Umaña-Taylor \& Alfaro, 2009). Moreover, the emphasis of acculturative stress on stress related to the process of cultural adaptation distinguishes it from other separate but related culturally-based stressors such as discrimination.

Several studies have documented evidence of a significant direct relationship between acculturative stress and Latino mental and physical health outcomes, including depression symptom severity (Crockett et al., 2007; Finch, Kolody, \& Vega, 2000; Torres, 2010), self-reported physical health (Finch, Hummer, Kolody, \& Vega, 2001), suicidal ideation (Hovey, 2000), and anxiety symptom severity (Hovey \& Magaña, 2000). Research has expanded upon these findings by examining possible psychosocial resources that may influence the acculturative stress-psychological adjustment relationship. For example, Crockett and colleagues (2007) found that active coping buffered against adverse psychological outcomes. At high levels of acculturative stress, Latinos who reported high active coping exhibited significantly lower depression symptom severity compared to Latinos who reported low active coping. Similarly, in an examination of the ability of acculturative stress to differentiate between low, medium, and high levels of depression severity, Torres (2010) found that increases in active coping styles were associated with a protective effect among Latinos who reported high depression symptom severity. This research is in keeping with stress and coping frameworks that suggest that the specific resources implemented to navigate stressors 
and stressful life events can influence psychological adjustment (Lazarus \& Folkman, 1984).

Building on stress and coping frameworks, Chun and colleagues (2006) suggested that cultural adaptation processes influence the intended goal to be achieved through coping. This in turn influences the selection of psychological resources used as a particular coping strategy. On the one hand, if the focus of the coping response is to minimize threat through the direct management of external stressors and situations, the relationship of acculturative stress to Latino psychological adjustment may be mediated by behavioral coping strategies such as active coping. On the other hand, self-efficacy emphasizes cognitive beliefs and expectations that one will successfully overcome obstacles and challenges (Bandura, 1977), suggesting that it may play an important role in Latino psychological functioning when the focus of coping is to manage internal experiences (e.g., cognitive or affective states). For example, a recent metaanalysis of 51 studies on the role of coping resources in Latinos' psychological adjustment found evidence of a moderate effect such that greater levels of positive self-concept and personal competence (i.e., self-efficacy) were associated with lower depression and anxiety (Lee \& Ahn, 2011). Similarly, prior research with Latina adolescents found that confidence and beliefs in one's competencies was related to significantly less dysphoria (Locke, Newcomb, Duclos, \& Goodyear, 2007). Furthermore, self-efficacy's focus on internal self-regulation through cognitive processes such as self-reflection and planning may contribute to other secondary control coping resources such as cognitive reappraisal and emotion-focused coping (Lazarus \& Folkman, 1984; Yeh, Kwon Arora, \& Wu, 2006), and therefore may indirectly influence the relationship of acculturative stress to Latino psychological adjustment. In particular, self-efficacy may be an effective resource to the degree that it contributes to the regulation of self-relevant cognitions that influence whether acculturative stressors are perceived as threatening. For example, those individuals who experience greater levels of acculturative stress may perceive themselves as less able to effectively overcome obstacles and challenges, which in turn may be associated with worse psychological adjustment. Consequently, the relation of Latinos' acculturative stress to psychological adjustment may be mediated by behavioral strategies that seek to alter situational factors associated with cultural stressors (i.e., active coping), cognitive

Cultural Diversity and Ethnic Minority Psychology, Vol 19, No. 4 (October 2013): pg. 373-382. DOI. This article is (c) American Psychological Association and permission has been granted for this version to appear in e-

Publications@Marquette. American Psychological Association does not grant permission for this article to be further copied/distributed or hosted elsewhere without the express permission from American Psychological Association. 
resources that instill a sense of resiliency in Latino individuals' ability to overcome acculturative stress (i.e., self-efficacy), or both.

The present study, therefore, compared behavioral and cognitive resources - active coping and self-efficacy, respectively - as variables that influence the relationship of acculturative stress to depression among Latino adults. Because the primary objective of this study was the examination of mechanisms by which cultural-based stressors influence Latino psychological adjustment (cf., Torres, 2009; Torres et al., 2012), a mediational analytic approach was used. To test the ability of active coping and self-efficacy to mediate the acculturative stress-depression relationship the present study used a multiple mediation analysis (Preacher \& Hayes, 2008), which permits the simultaneous test of more than one potential mediator. Congruent with prior research, it was hypothesized that acculturative stress would be significantly related to greater severity of depression symptoms. Furthermore, based on prior research that has found a significant relationship between acculturative stress and Latino psychological adjustment, it was expected that acculturative stress would remain a significant predictor of depression after accounting for the influence of active coping and self-efficacy. It was further hypothesized that active coping and self-efficacy would significantly mediate the relationship of acculturative stress to depression. Specifically, it was predicted that greater acculturative stress would be significantly related to lower active coping and lower self-efficacy, and that these in turn would be significantly related to greater depression symptom severity. To our knowledge, no prior research has investigated the concurrent indirect relationships of acculturative stress to Latino depression symptom severity as mediated by behavioral and cognitive resources. Thus, no hypotheses were proposed regarding whether the specific indirect relationship of acculturative stress to depression would be stronger through active coping as compared to self-efficacy.

\section{Method}

\section{Participants and Demographic Characteristics}

The participants for the present study consisted of a community sample of Latina/o adults $(N=469)$ who were residents of a 
moderately-sized Midwestern city. Latinos comprise $17.6 \%$ of the population of the city in which participants were recruited (U.S. Census Bureau, 2010), which is somewhat higher compared to the proportion of the population that identifies as Latino at state and national levels (5.9\% and $16.4 \%$, respectively; Pew Hispanic Center, 2012). The mean reported age of the sample was 39 years old $(S D=14.32)$. More women $(67.28 \%, n=306)$ than men $(32.2 \%, n=145)$ participated. Most participants were either married $(50.8 \% n=234)$ or single $(30.8 \%, n=142)$, with two or fewer children living at home (73.4\%, $n=320)$. Approximately $41 \%(n=186)$ of the sample was foreign-born. The majority of participants identified their cultural background as Mexican, Mexican-American, or Chicano $(84.0 \%, n=$ 382), although Puerto Rican, Cuban, Central American, and South American cultural backgrounds were also represented. The mean number of years lived in the United States was 30.26 ( $S D=18.01$ ). The mean percentage of participants' lives spent residing in the United States, defined as the quotient of participant's self-reported years lived in the United States divided by age, was $76.98 \%(S D=31.52)$.

Household income was distributed evenly across the sample. Approximately one-third of the sample $(29.7 \%, n=130)$ reported their household income as $\$ 50,000$ or greater, $22.1 \%(n=97)$ reported $\$ 35,000-\$ 50,000,21.7 \%(n=95)$ reported $\$ 20,000-$ $\$ 35,000$, and $26.5 \%(n=116)$ reported a household income of less than $\$ 20,000$. Compared to 2010 ACS one-year estimates for Latino households in this community, there were similar proportions in the present sample of household incomes greater than $\$ 50,000(28.84 \%$ vs. $29.7 \%$, respectively), $\$ 20,000-\$ 35,000$ (25.69\% vs. $21.2 \%$, respectively), and under $\$ 20,000$ (25.79\% vs. $26.5 \%$, respectively; U.S. Census, 2010). In contrast, compared to the 2010 ACS, the present sample contained a greater proportion of individuals who had a total household income of $\$ 35,000-\$ 50,000$ (16.27\% vs. $22.1 \%$, respectively). Overall, participants were well-educated: $18.2 \%$ ( $n=$ 83) had a bachelor's degree or higher, one-third reported they had completed at least one year of college $(31.0 \%, n=141), 27.0 \%(n=$ 123) had a high school diploma or equivalent degree, and $23.7 \%$ ( $n=$ 108) had 11 years or fewer education. 
NOT THE PUBLISHED VERSION; this is the author's final, peer-reviewed manuscript. The published version may be accessed by following the link in the citation at the bottom of the page.

\section{Procedure}

Study participants were recruited from the community at various local culturally-based events. Participants completed a packet of questionnaires that asked about demographic information, acculturative stress, self-efficacy, active coping strategies, and severity of depression symptoms (see Measures section below). Spanish- and English-language versions of all study measures were available to participants and were administered in participants' stated preferred language. The majority of participants $(65.0 \%, n=305)$ elected to complete study measures in English. Participants received a $\$ 10$ gift card as compensation for completion of study measures. All procedures were approved by, and in compliance with, the sponsoring institution's Institutional Review Board (IRB).

\section{Measures}

\section{Acculturative stress}

The Multidimensional Acculturative Stress Inventory (MASI; Rodriguez et al., 2002) assessed participants' acculturative stress. The MASI is a 36-item instrument that measures acculturative stress that originates from European American (e.g., "It bothers me that I speak English with an accent") and Latino sources (e.g., "I feel pressure to learn Spanish"). Specifically, the MASI assesses severity of acculturative stress related to competency of language use (English and Spanish), pressures to acculturate to the majority culture, and pressure against acculturation to the majority culture. Respondents rate items according to the perceived amount of acculturative stress experienced during the previous three months on a six-point scale ranging from 0 (does not apply) to 5 (extremely stressful). Items are averaged to obtain an overall score that ranges from 0 to 5 , where higher MASI scores correspond to greater acculturative stress. Prior studies with the MASI have reported good to excellent internal consistency and test-retest reliability (Rodriguez et al., 2002; Schwartz \& Zamboanga, 2008). The MASI has also been found to predict psychological distress above and beyond sociodemographic variables (Rodriguez et al., 2002) and differentially predict severity of depression levels (e.g., low, medium, and high) among Latinos

Cultural Diversity and Ethnic Minority Psychology, Vol 19, No. 4 (October 2013): pg. 373-382. DOI. This article is (c) American Psychological Association and permission has been granted for this version to appear in e-

Publications@Marquette. American Psychological Association does not grant permission for this article to be further copied/distributed or hosted elsewhere without the express permission from American Psychological Association. 
NOT THE PUBLISHED VERSION; this is the author's final, peer-reviewed manuscript. The published version may be accessed by following the link in the citation at the bottom of the page.

(Torres, 2010). Among the present sample, the MASI demonstrated excellent internal consistency (see Table 1).

Table 1

Correlations, Means, and Standard Deviations for Study Variables

\begin{tabular}{|c|c|c|c|c|c|c|c|c|}
\hline & 1 & 2 & 3 & 4 & 5 & 6 & 7 & 8 \\
\hline 1. Age & -- & & & & & & & \\
\hline 2. Education Level & -0.05 & -- & & & & & & \\
\hline 3. Household Income & $.08^{*}$ & $.34^{* * *}$ & -- & & & & & \\
\hline $\begin{array}{l}\text { 4. Number of Years Lived } \\
\text { in the U.S. }\end{array}$ & $.73 \stackrel{* * *}{2}$ & $.19 * * *$ & $.28^{* * *}$ & -- & & & & \\
\hline 5. Acculturative Stress & $-0.12^{*}$ & $-.12 *$ & $-.29 * * *$ & $-.15^{* *}$ & $(.92)$ & & & \\
\hline 6. Active Coping & .08 & $.21^{* * *}$ & $.24^{* * *}$ & .04 & $-.25^{* * *}$ & $(.69)$ & & \\
\hline 7. Self-Efficacy & .04 & $.13^{* *}$ & $.17^{* * *}$ & .04 & $-.11^{*}$ & $.38^{* * *}$ & $(.93)$ & \\
\hline 8. Depression & $-.13^{* *}$ & $-.12 *$ & $-.29^{* * *}$ & -.06 & $.33^{* * *}$ & $-.41 * * *$ & $-.20^{* * *}$ & $(.84)$ \\
\hline$M$ & 39.16 & -- & -- & 30.26 & 1.52 & 8.46 & 31.81 & 7.89 \\
\hline$S D$ & 14.32 & -- & -- & 18.01 & 0.57 & 2.58 & 6.43 & 5.96 \\
\hline
\end{tabular}

Note. Where applicable, numbers presented along the diagonal correspond to scale internal consistency. Spearman correlations reported for education level and household income. All other correlations are Pearson correlations.

${ }^{*} p<.05^{* *} p<.01{ }^{* * *} p<.001$

\section{Active coping}

The Behavioral Attributes of Psychosocial Competence Condensed Form (BAPC-C; Zea, Reisen, \& Tyler, 1996) assessed participant active coping style. The BAPC-C is a 13-item self-report questionnaire of psychosocial competence culturally specific to the mainstream United States. To assess behavioral coping strategies, participants select from a series of dichotomous forced-choice items the statement that more closely describes their typical actions. Each forced-choice item contains one active behavioral coping strategy (e.g., "I usually think ahead and organize my thoughts or ideas about future situations") and one passive behavioral coping strategy (e.g., "I generally prefer to live my life as I go"). Active behavioral coping strategies receive a score of 1 , whereas passive behavioral coping strategies receive a score of 0 . BAPC-C items are summed to obtain a single measure of behavioral coping strategies with scores ranging from 0 to 13. Higher scores indicate greater use of active coping. The BAPC-C has been found to be a reliable and valid measure of coping behaviors among several ethnic groups including African Americans,

Cultural Diversity and Ethnic Minority Psychology, Vol 19, No. 4 (October 2013): pg. 373-382. DOI. This article is (C) American Psychological Association and permission has been granted for this version to appear in e-

Publications@Marquette. American Psychological Association does not grant permission for this article to be further copied/distributed or hosted elsewhere without the express permission from American Psychological Association. 
Asian Americans, Latinos, and non-Latino European Americans (Torres, 2009; Torres, Driscoll, \& Burrow, 2010; Zea, Belgrave, Townsend, Jamara, \& Banks, 1996; Zea et al., 1996). In the present sample, the BAPC-C internal consistency as measured by Cronbach's alpha was .69 (see Table 1), which is slightly below the recommended cutoff of .70 for adequate internal consistency (Kline, 2005). However, the Cronbach's alpha obtained for this sample was similar to those obtained by other studies that have also used the BAPC-C with Latino samples (cf. Torres, 2009; Torres, 2010; Zea et al., 1996).

\section{Self-efficacy}

The General Self-Efficacy Scale (GSE; Schwarzer \& Jerusalem, 1995) measured participant self-efficacy. The GSE is a ten-item, selfreport questionnaire that assesses orientation toward an attitude that one possesses the capacity and resilience to cope with and overcome challenges imposed by situational stressors. That is, the GSE does not assess specific styles of coping or the frequency of actual behavioral strategies employed, but rather measures respondents' perception of their personal efficacy or competence to effectively deal with stressful situations. Sample scale items include "I am certain I can accomplish my goals," and "I am confident that I can deal efficiently with unexpected events." Respondents rate the degree to which they believe scale items are true of them on a Likert scale that ranges from 1 (not at all true) to 4 (exactly true). Scale items are summed to obtain a total self-efficacy score that ranges from 10 to 40 . Higher scores correspond to greater self-efficacy. The GSE is a widely-used measure of self-efficacy and has been translated into over 25 languages. The GSE has shown evidence of good to excellent reliability in prior research, with internal consistency coefficients ranging from .75 to .91 (Scholz, Doña, Sud, \& Schwarzer, 2002). Confirmatory factor analysis (CFA) across samples from 25 countries has supported that the GSE measures self-efficacy as a unidimensional construct across multiple cultures, and has found to be negatively associated with anxiety and depression (Scholz et al., 2002). As shown in Table 1, the GSE demonstrated excellent internal consistency in the present sample. 
NOT THE PUBLISHED VERSION; this is the author's final, peer-reviewed manuscript. The published version may be accessed by following the link in the citation at the bottom of the page.

\section{Depression}

The Brief Center for Epidemiological Studies - Depression Scale (BCES-D; Kohout, Berkman, Evans, \& Cornoni-Huntley, 1993) assessed severity of participant depression symptoms. The BCESD is a ten-item self-report measure of affective, somatic, cognitive, and interpersonal components of depression. Respondents rate the frequency with which they have experienced scale items within the past week on a Likert-scale that ranges from 0 (Rarely or none of the time) to 3 (Most or all of the time). Scale items are summed and range from 0 to 30, with higher scores indicating greater depression symptom severity. Although developed with a non-clinical population and not intended for use as a diagnostic instrument, the BCES-D has been found to be a sensitive measure of depression symptoms among community samples of Latinos (Grzywacz, Hovey, Seligman, Arcury, \& Quandt, 2006; Grzywacz, Quandt, Chen, Isom, Kiang, Vallejos, et al., 2010). Prior research on the factor structure and internal consistency of the BCES-D among community samples of immigrants from Mexico found that the BCES-D demonstrated good internal consistency, as well as equivalency to the full version of the Center for Epidemiological Studies-Depression Scale (CES-D; Radloff, 1977) with regard to factor structure, proportion of variance accounted for among respondent scores, and correlations with anxiety, social support, and acculturative stress (Grzywacz et al., 2006). Among the present sample, the BCESD demonstrated good internal consistency (see Table 1).

\section{Results}

\section{Descriptive Statistics and Preliminary Analysis}

Table 1 presents means, standard deviations, internal consistencies, and bivariate correlations among major study variables. The mean MASI score suggests that, on average, the participants in the present study experienced lower levels of acculturative stress, and this score was somewhat lower compared to mean MASI scores that have been reported in prior studies (cf. Umaña-Taylor, Updegraff, \& Gonzales-Backen, 2011). With regard to behavioral and cognitive resources, participants in the present study on average reported high levels of self-efficacy and engaged in moderately-high levels of active

Cultural Diversity and Ethnic Minority Psychology, Vol 19, No. 4 (October 2013): pg. 373-382. DOI. This article is (c) American Psychological Association and permission has been granted for this version to appear in e-

Publications@Marquette. American Psychological Association does not grant permission for this article to be further copied/distributed or hosted elsewhere without the express permission from American Psychological Association. 
coping behaviors. Bivariate correlations indicated that, for participants in the present study, greater acculturative stress was significantly associated with lower age, less education, lower household income, fewer years lived in the United States, lower active coping and selfefficacy, and greater depression. Active coping and self-efficacy were significantly associated with higher education and household income, as well as lower depression. Higher depression scores were significantly associated with lower age, education, and household income. Due to these significant correlations, age, education level, and household income were covaried in the main analyses. Number of years lived in the United States was not covaried in the main analyses because it was highly correlated with participant age $(r=.73)$, suggesting these two variables are multicolinear, and because it was conceptually redundant with participant nativity status (see following paragraph).

Independent samples $t$-tests and chi-square tests of independence were conducted to examine whether there were significant differences among participants with regard to nativity status (foreign - vs. U.S.-born) and gender. Compared to U.S.-born Latinos, a significantly greater proportion of foreign-born Latinos reported lower household income, $\mathrm{x}^{2}(5)=18.04, p=.003$. Additionally, foreign-born Latinos were significantly younger than U.S.-born Latinos $(M=37.30, S D=12.57$ vs. $M=40.09, S D=15.23$, respectively $), t$ $(397)=-2.05, p=.04$; and had lived in the United States for significantly fewer years $(M=38.84, S D=15.50$ vs. $M=17.70, S D=$ 13.36 , respectively), $t(418)=-14.56, p<.001$. No significant differences between participant nativity status was found for acculturative stress, self-efficacy, active coping, and depression symptom severity. Compared to men, women reported higher active coping ( $M=7.84, S D=2.52$ vs. $M=8.72, S D=2.58$, respectively $), t$ $(433)=-3.35, p=.001$; and higher self-efficacy $(M=30.79, S D=$ 7.14 vs. $M=32.22, S D=6.05$, respectively, $t(435)=-2.18, p=.03$. No other significant gender differences were found for age, household income, years lived in the United States, acculturative stress, and depression scores. Due to these significant differences, nativity status and gender were subsequently covaried in hypothesis testing.

Cultural Diversity and Ethnic Minority Psychology, Vol 19, No. 4 (October 2013): pg. 373-382. DOI. This article is (c) American Psychological Association and permission has been granted for this version to appear in ePublications@Marquette. American Psychological Association does not grant permission for this article to be further copied/distributed or hosted elsewhere without the express permission from American Psychological Association. 
NOT THE PUBLISHED VERSION; this is the author's final, peer-reviewed manuscript. The published version may be accessed by following the link in the citation at the bottom of the page.

\section{Primary Analysis and Hypothesis Testing}

\section{Analytic procedure}

Tests of the relationship between acculturative stress and depression as mediated by self-efficacy and active coping were conducting using a multiple mediation procedure and macro developed by Preacher and Hayes (2008). Similar to structural equation modeling (SEM), multiple mediation statistical approaches test the significance of the indirect effect of a predictor variable on a criterion or outcome variable through hypothesized mediator variables, as well as the direct effect of a predictor variable on a criterion. An advantage of the multiple mediator statistical approach is that it permits assessment of the significance of the relationship between the predictor and criterion variables through a set of mediator variables, or the total indirect effect, in addition to statistical comparisons of the significance of one indirect effect- or specific indirect effect - relative to another indirect effect. Thus, multiple mediation determines whether a significant overall indirect effect of the set of proposed mediators is present, in addition to the relative importance of one proposed mediator variable relative to another (Preacher \& Hayes, 2008). Due to skewed distributions with respect to MASI, BAPC-C, GSE, and BCES-D scores, bootstrapped resampling procedures were also conducted to test for indirect effects as recommended by Preacher and Hayes (2008). An advantage to this procedure is that bootstrapped estimates do not impose assumptions of univariate and multivariate normality with respect to sampling distributions. Whereas sampling distributions that violate normality may decrease the power of inferential statistics - and thus produce inaccurate estimates of mediational effects bootstrapped estimates in multiple mediation are derived from the distribution of direct and indirect effects from which confidence intervals are calculated, and as such upper and lower bounds of estimated confidence intervals are not required to be equidistant from the sample mean (Preacher \& Hayes, 2008; Shrout \& Bolger, 2002).

\section{Multiple mediator analysis}

Figure 1 presents the full multiple mediator model. The overall model was significant, $\mathrm{R}^{2}=.26, F(8,354)=15.37, p<.001$. The $\mathrm{R}^{2}$ 
value indicates that the overall model accounted for $26 \%$ of the variance in predicting depression symptom severity scores. As shown in Figure 1, the total effect of acculturative stress on depression was significant and suggested that greater acculturative stress was related to greater depression symptom severity, $t=4.75, p<.001$. As expected, greater acculturative stress was significantly related to lower active coping $t=-3.25 p=.001$, and lower active coping was significantly related to greater severity of depression symptoms, $t=$ $-6.01, p<.001$ (see Figure 1 ). Contrary to study predictions, acculturative stress was not related to self-efficacy $t=-0.64, p=.52$, and self-efficacy was not related to severity of depression symptoms, $t$ $=-0.80 p=.42$ (see Figure 1). Figure 1 also shows that the direct effect of acculturative stress on depression severity symptoms was significant, $t=3.85, p<.001$, suggesting that acculturative stress was significantly related to greater depression after accounting for the indirect relationship of acculturative stress to depression through selfefficacy and active coping.

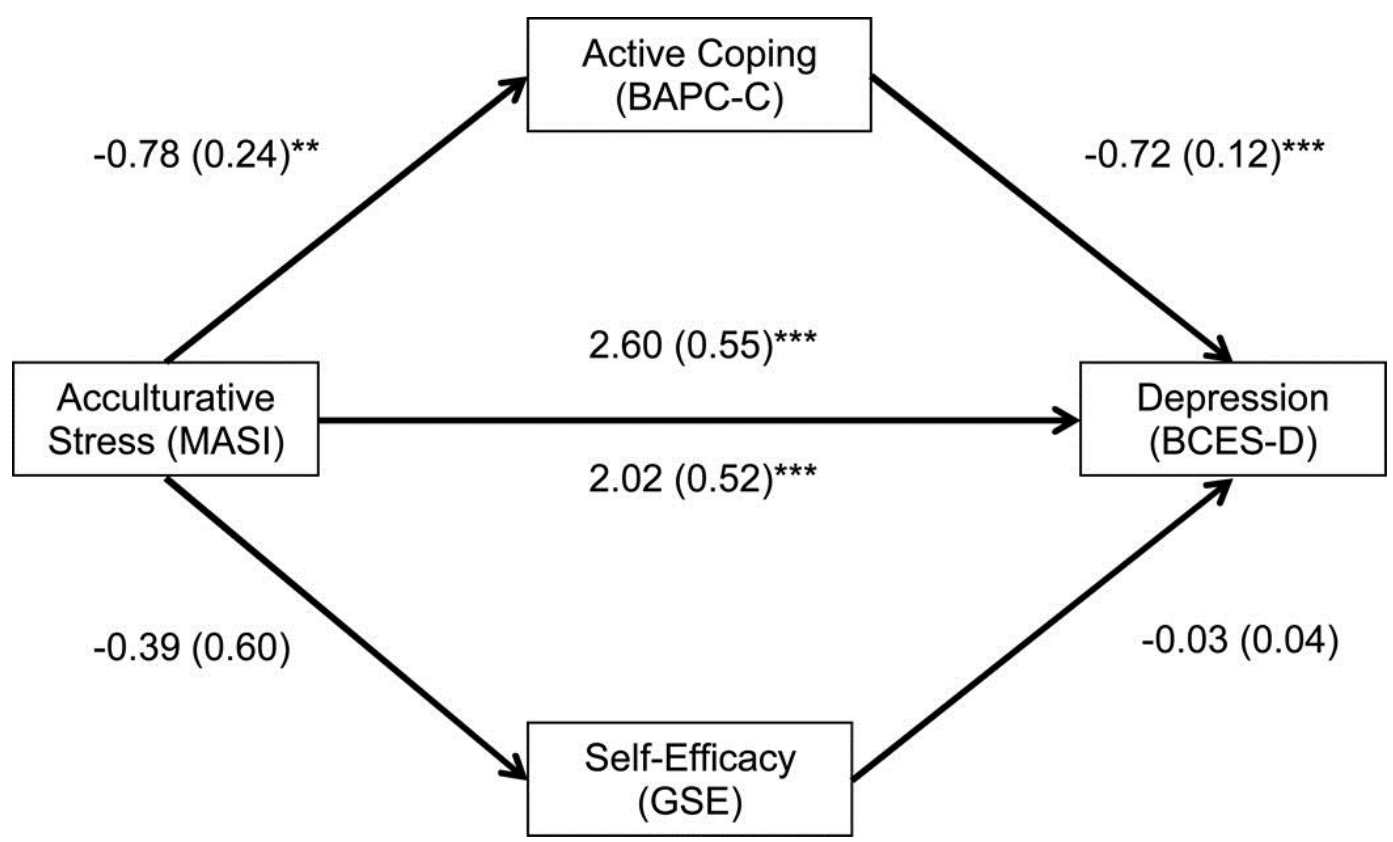

Figure 1. Multiple Mediator Model of the Indirect Effect of Acculturative Stress on Depression through Behavioral and Cognitive Resources

Note. Unstandardized Beta coefficients shown. Numbers in parentheses represent standard error terms. The number above the line between acculturative stress and depression denotes the total effect; the number below the line between acculturative stress and depression denotes the direct effect after accounting for the indirect effects of self-efficacy and active coping.

$* \mathrm{p}<.05 * * \mathrm{p}<.01 * * * \mathrm{p}<.001$

Cultural Diversity and Ethnic Minority Psychology, Vol 19, No. 4 (October 2013): pg. 373-382. DOI. This article is (C) American Psychological Association and permission has been granted for this version to appear in e-

Publications@Marquette. American Psychological Association does not grant permission for this article to be further copied/distributed or hosted elsewhere without the express permission from American Psychological Association. 
The indirect relationship of acculturative stress on severity of depression symptoms through the hypothesized mediators of active coping and self-efficacy are presented in Table 2. Tests of significance with regard to the total indirect effect of acculturative stress on severity of depression symptoms through the hypothesized mediators are shown, as well as the specific indirect effect through each proposed mediator. The z-score for the total indirect effect of selfefficacy and active coping was significant, and indicated that a onepoint increase in acculturative stress was associated with approximately a 0.58 increase in participants' depression symptom severity scores through their corresponding relationships with selfefficacy and active coping. Although Table 2 indicates that the total indirect effect was significant, the direct effect of acculturative stress on depression remained significant after accounting for its total indirect effect through the hypothesized mediators (see Figure 1). Thus, active coping and self-efficacy partially, rather than fully, mediated the relationship between acculturative stress and severity of depression symptoms (Baron \& Kenny, 1986; Shrout \& Bolger, 2002).

Table 2. Indirect Effects, Tests of Mediation, Bootstrap Point Estimates, 95\% Confidence Intervals, and Contrasts of Specific Indirect Effects for Multiple Mediator Model

\begin{tabular}{|c|c|c|c|c|c|c|}
\hline \multirow[b]{2}{*}{$\begin{array}{l}\text { Indirect } \\
\text { Effect }\end{array}$} & \multirow[b]{2}{*}{$\begin{array}{c}\text { Point } \\
\text { Estimate } \\
\text { of Indirect } \\
\text { Effect }\end{array}$} & \multicolumn{2}{|c|}{$\begin{array}{l}\text { Product of } \\
\text { Coefficients }\end{array}$} & \multirow[b]{2}{*}{$\begin{array}{c}\text { Bootstrap } \\
\text { Estimate } \\
\text { of Indirect } \\
\text { Effect }\end{array}$} & \multicolumn{2}{|c|}{$\begin{array}{l}\text { Bootstrap } 95 \% \\
\text { Confidence } \\
\text { Interval }\end{array}$} \\
\hline & & $S E$ & $\mathbf{Z}$ & & $\begin{array}{l}\text { Lower } \\
\text { Bound }\end{array}$ & $\begin{array}{l}\text { Upper } \\
\text { Bound }\end{array}$ \\
\hline Self-Efficacy & 0.0148 & 0.0489 & 0.303 & 0.0123 & -0.0455 & 0.1833 \\
\hline Active Coping & 0.5643 & 0.1873 & $3.013^{* *}$ & 0.5666 & 0.2594 & 0.9960 \\
\hline $\begin{array}{l}\text { Total Indirect } \\
\text { Effect }\end{array}$ & 0.5790 & 0.1966 & $2.945^{* *}$ & 0.5789 & 0.2364 & 1.0064 \\
\hline \multicolumn{7}{|c|}{$\begin{array}{l}\text { Contrasts of Specific Indirect } \\
\text { Effects }\end{array}$} \\
\hline Active Coping & 0.5495 & 0.1905 & $2.885^{* *}$ & 0.5542 & 0.2424 & 0.9997 \\
\hline
\end{tabular}

Note. Bootstrapped point estimates are for $k=5,000$ samples. $95 \%$ confidence intervals shown are bias corrected and accelerated.

$* p<.05 * * p<.01 * * * p<.001$

Cultural Diversity and Ethnic Minority Psychology, Vol 19, No. 4 (October 2013): pg. 373-382. DOI. This article is (c) American Psychological Association and permission has been granted for this version to appear in e-

Publications@Marquette. American Psychological Association does not grant permission for this article to be further copied/distributed or hosted elsewhere without the express permission from American Psychological Association. 
Table 2 presents the decomposition of the total indirect effect into the corresponding specific indirect effects of acculturative stress on depression through self-efficacy and active coping. As shown, the zscore for the specific indirect effect for active coping was statistically significant and indicated that a one-point increase in acculturative stress was significantly associated with a 0.43 increase in depression through active coping (see Table 2). The z-score for the specific indirect effect for self-efficacy, however, was not statistically significant, suggesting that acculturative stress was not significantly related to severity of depression symptoms through lowered selfefficacy. Contrasts of specific indirect effects suggest that the specific indirect effect of active coping was significantly greater than the specific indirect effect of self-efficacy (see Table 2). Thus, the results suggest that active coping, but not self-efficacy, partially mediates the relationship of acculturative stress to depression. $\frac{1}{}$

As recommended by Preacher and Hayes (2008), bootstrapping estimates of indirect effects for 5,000 samples were generated to test whether the indirect effect of acculturative stress on depression symptom severity through self-efficacy and active coping was significant. Table 2 presents the subsequent $95 \%$ confidence intervals and indirect effect estimates for bootstrapped resampling procedures. These results derive a point estimate of the bootstrap effect size. A significant indirect effect is denoted by a $95 \%$ confidence interval that does not contain a zero value in its upper and lower bounds. As shown in Table 2, bootstrap estimates of indirect effect sizes yielded results that were similar to the above analyses. After generating bootstrap estimates for 5,000 samples, the $95 \%$ confidence intervals for the total indirect effect as well as the specific indirect effect of acculturative stress on depression through active coping did not contain zero, indicating that these indirect effects were significant. In contrast, the lower and upper bounds of the $95 \%$ confidence interval for the indirect effect of acculturative stress on depression through self-efficacy were -.0455 and .1833 , respectively (see Table 2). Because a zero value is contained within the lower and upper bounds of the $95 \%$ confidence interval, the bootstrap estimates indicate that this indirect effect was not significant. Thus, bootstrap estimates to correct for potential estimate bias in the sampling distribution did not yield different results from initial analyses. 
NOT THE PUBLISHED VERSION; this is the author's final, peer-reviewed manuscript. The published version may be accessed by following the link in the citation at the bottom of the page.

\section{Discussion}

The present study tested behavioral and cognitive resources as possible mediators of the relationship between acculturative stress and depression symptom severity among a sample of Midwestern Latino adults. This research was informed by cultural stress and coping frameworks that emphasize the importance of cultural background in shaping whether individuals implement coping strategies to directly manage external stressors versus managing internal states (Chun et al., 2006). A particular strength of the statistical technique employed in the present study is that it permitted the analysis of multiple mediators in a single statistical model. This approach addresses limitations of simple mediational analysis where an observed direct relationship between a predictor variable and a criterion may reflect either a true relationship or residual unexplained variance due to the omission of additional mediating variables (Preacher \& Hayes, 2008).

The study's results partially supported the hypotheses. As expected, acculturative stress was directly related to greater depression. After accounting for indirect effects, the relationship of acculturative stress to depression symptom severity was reduced but remained significant, suggesting partial mediation. As hypothesized, acculturative stress was associated with lower active coping strategies, which was in turn associated with greater depression symptom severity, and this indirect relationship was significant. Contrary to study hypotheses, however, the indirect relationship of acculturative stress to depression symptom severity through self-efficacy was not significant. Taken together, these results suggest that acculturative stress is directly related to greater depression symptom severity among Latinos, and that lowered active coping significantly contributes to the observed relationship between acculturative stress and depression. Although lower self-efficacy may be related to psychological adjustment in general, the present study suggests that active coping may be a more adequate match to acculturative stress demands and related psychological consequences.

The findings of the present study underscore the role of acculturative stress as an important form of culturally-based stress. Although Latinos are exposed to many psychosocial stressors that

Cultural Diversity and Ethnic Minority Psychology, Vol 19, No. 4 (October 2013): pg. 373-382. DOI. This article is (c) American Psychological Association and permission has been granted for this version to appear in e-

Publications@Marquette. American Psychological Association does not grant permission for this article to be further copied/distributed or hosted elsewhere without the express permission from American Psychological Association. 
potentially influence psychological functioning (e.g., discrimination, separation from family due to immigration), the finding that acculturative stress significantly predicted greater depression after accounting for indirect effects suggests that stress associated with the process of cultural adaptation specifically contributes to severity of depression symptoms among Latinos. Congruent with this interpretation, Torres and colleagues (2012) found that acculturative stress partially mediated the relationship of discrimination to Latino psychological distress, indicating that acculturative stress exhibits a relationship with Latino psychological functioning that is independent of that conferred by other stressors such as discrimination. Moreover, prior research indicates that individual variations in the perception of the compatibility of cultural identities are related to the ability to respond to culturally-relevant situational cues with culturallycongruent behavior (Benet-Martínez, Leu, Lee, \& Morris, 2002). Potentially, those Latinos who view their Latino and mainstream American cultural identities as conflicting may experience greater challenges shifting between cultural frames of reference such that situation-incongruent expression of behaviors and practices associated with mainstream culture and Latino cultural background contributes to greater acculturative stress. Accordingly, the results of the present study build on prior research to suggest that acculturative stress, and in particular stress associated with the perceived demands of behavioral and cognitive adjustment to another culture while concurrently maintaining behaviors and practices of one's cultural heritage, is in itself associated with greater severity of symptoms of depression for Latinos.

Findings of the present study also advance prior research with regard to culturally-based stress and Latino psychological adjustment by clarifying potential mechanisms by which acculturative stress influences depression symptom severity. In particular, the significant indirect relationship of acculturative stress to greater depression through lower active coping suggests that acculturative stress is associated with depression partially through a decreased engagement in active, effortful behavioral strategies that directly manage contextual and environmental stressors. As suggested by transactional stress and coping models, the degree to which life events are perceived as stressful, and subsequently influence psychological functioning, partially depends on the degree to which coping strategies 
effectively address the specific demands of situational stressors (Lazarus \& Folkman, 1984). Moreover, use of specific coping strategies is influenced by whether particular coping styles are perceived as valued and reinforced by cultural context and environment (Chun et al., 2006; Garcia Coll, Akerman, \& Cichetti, 2000; Ogbu, 1981). Greater use of active coping strategies may be more congruent with behaviors and preferences associated with mainstream American culture, as opposed to coping strategies that may be more commonly used by Latinos who have stronger behavioral retention of their cultural heritage, such as social support, family support, or emotionfocused coping (Umaña-Taylor \& Alfaro, 2009). Those Latinos who exhibit greater retention of behaviors associated with their cultural background may experience increased pressure to assimilate to majority American culture. Paradoxically, however, these very individuals may also be less likely to implement the active coping strategies that have been found to be related to lower depression among Latinos (Crockett et al., 2007; Torres, 2009; Torres, 2010).

Cognitive resources such as self-efficacy have been associated with lower depression in previous research (Abraido-Lanza, Vásquez, \& Echeverría, 2004; Lee \& Ahn, 2012; Locke et al., 2007; Scholz et al., 2002), and thus the finding that self-efficacy was related to neither acculturative stress nor depression was unexpected. Although prior studies have documented that self-efficacy is related to lower levels of other forms of culturally-based stressors such as discrimination (Lee \& Ahn, 2012), no prior research has examined self-efficacy as a resource variable that specifically mediates the relationships between acculturative stress and Latino psychological functioning. Nonetheless, one's belief in the ability to effectively address life challenges appears to be unrelated to stress associated with cultural adaptation and depression in the present study. Possibly, Latinos may be more likely to appraise acculturative stress as a threat to psychological functioning, and therefore may be more likely to engage in active coping strategies, which have a greater potential to minimize threat and harm compared to cognitive resources such as self-efficacy.

Cultural Diversity and Ethnic Minority Psychology, Vol 19, No. 4 (October 2013): pg. 373-382. DOI. This article is (c) American Psychological Association and permission has been granted for this version to appear in e- 
NOT THE PUBLISHED VERSION; this is the author's final, peer-reviewed manuscript. The published version may be accessed by following the link in the citation at the bottom of the page.

\section{Limitations}

A few study limitations warrant comment. First, the findings of the present study are based on cross-sectional design, which limits the ability to infer causal relationships among acculturative stress, active coping, and depression symptom severity. Causal interpretations should be considered provisional pending replication in future research employing longitudinal methods. A second limitation is the small portion of Latinos who identified as having a cultural background other than Mexican, Mexican-American, or Chicano. Prior researchers have found differences in lifetime prevalence of psychiatric disorders across Latino subgroups (Alegria et al., 2007), which may be partially explained by Latino subgroups' unique acculturative histories (Balls Organista, Organista, \& Kurasaki, 2003). The results of the present study should be replicated with larger samples of different Latino subgroups to assess whether the relationship of acculturative stress and active coping to depression symptom severity generalizes across groups of Latinos. Third, regional demographics may have influenced the study's results. Although the proportion of Latinos living in the city where this study was conducted is similar to the percentage of Latinos living in the United States overall, at the state level Latinos comprise less than six percent of the general population (Pew Hispanic Center, 2012). It is possible that the overall lower representation of Latinos in this geographic region may have contributed to greater assimilation of typical Western behaviors and characteristics. Thus, the results should be replicated in other regions and communities where larger numbers of Latinos reside. Finally, the present study did not control for other stressors such as discrimination, general life stress, or interpersonal stressors. Consequently, the observed relationship between acculturative stress and depression may have been augmented to the extent that they share a mutual relationship with other types of stressors.

\section{Implications and Conclusions}

The present study's results suggest potential implications for assessment and intervention for clinicians engaged in therapeutic treatment of Latinos. The finding that acculturative stress directly influenced depression symptom severity suggests that acculturative

Cultural Diversity and Ethnic Minority Psychology, Vol 19, No. 4 (October 2013): pg. 373-382. DOI. This article is (c) American Psychological Association and permission has been granted for this version to appear in e-

Publications@Marquette. American Psychological Association does not grant permission for this article to be further copied/distributed or hosted elsewhere without the express permission from American Psychological Association. 
stress functions as an important contextual domain for Latinos that should assessed be in treatment. Assessment of acculturative stress in clinical settings may benefit treatment planning and intervention by providing a nuanced depiction of the various acculturative stressors that may challenge Latino clients (e.g., difficulty with acclimating to mainstream culture contexts, psychological distress related to conflicting cultural behaviors and identities). The study's results also suggest that therapeutic interventions that augment clients' active coping strategies may mitigate the influence of acculturative stress on depression. Studies of behavioral therapies indicate that active coping strategies are associated with lower depression among Latinos (Kanter, Santiago-Rivera, Rusch, Busch, \& West, 2010), and the present study suggests these findings may also apply to the relationship between depression and acculturative stress.

With regard to theoretical implications, additional research is necessary to further elucidate whether particular forms of acculturative stress are differentially associated with Latino psychological adjustment. For example, acculturative stress related to English competency pressures distinguishes Latinos with elevated depression symptoms from those with low depression symptoms (Torres, 2010). Given that individual characteristics such as nativity status and age at immigration (Alegria et al., 2008), reasons for immigration (Balls Organista et al., 2003), and acculturation have all been found to be associated with various mental health outcomes, it is possible that as each Latino individual's cultural adaption progresses, different forms of acculturative stress are experienced across the life span. Furthermore, most research that has examined the relationship of acculturative stress and Latino psychological adjustment from a stress and coping framework focuses on resources that have their basis in mainstream, White American cultural frameworks (e.g., Constantine, Okazaki, \& Utsey, 2004; Crocket et al., 2007; Torres, 2010). For this reason, it is important for future research to emphasize coping resources based on Latino cultural characteristics. Resources such as emotion-focused coping and family support that correspond to Latino cultural values of personalismo and familismo, respectively, may play a stronger role when acculturative stress results from pressures against acculturation, whereas active coping may play a stronger role when acculturative stress reflects greater pressure to acculturate. Thus, future research should endeavor for a more nuanced articulation of the potential 
interrelationships of acculturative stress and coping resources to clarify under what circumstances acculturative stress is associated with depression, and under what context specific coping styles influence their relationship.

Additionally, assessment of Latino individuals' self-construal, particularly with regard to collectivistic and individualistic orientations (Markus \& Kitayama, 1991; Oyserman, Coon, \& Kemmelmeier, 2002), may advance the present study's findings through the parsing of the specific roles of coping choice and coping effectiveness in the relationship of acculturative stress to Latino depression. Building on personality and stress-process frameworks (e.g., Chun et al., 2006; Bolger \& Zuckerman, 1995), those Latinos with more independent, individualistic orientations may be more likely to choose active coping strategies to negotiate acculturative stressors compared to those with more interdependent, collectivistic orientations. Alternately, for Latinos with higher individualistic orientations, active strategies may be more effective in buffering against the influence of acculturative stress on depression. Beyond the development of a more ecologically valid research agenda, the inclusion of collectivistic and individualistic orientations in future research may help guide culturally-responsive clinical interventions. For example, for some Latinos acculturative stressors may be effectively addressed through the promotion of active coping strategies as a result of a more independent, individualistic orientation, whereas for other Latinos coping strategies that are congruent with interdependent, collectivistic orientations may constitute a better fit.

In conclusion, this study examined the differential roles of active coping and self-efficacy as resources that partially confer the influence of acculturative stress to depression among Latinos. A major implication of this study is the relative importance of active coping, compared to self-efficacy, as a resource that mediates the relationship between acculturative stress and Latino psychological adjustment. Going forward, research should articulate the roles that different types of acculturative stress and culturally-based coping strategies play in the association between of acculturative stress and depression. Further investigation of the links between various forms of acculturative stress and coping will ultimately contribute to cultural adaptation processes 
NOT THE PUBLISHED VERSION; this is the author's final, peer-reviewed manuscript. The published version may be accessed by following the link in the citation at the bottom of the page.

that minimize adverse psychological outcomes and promote well-being among Latinos living in the United States.

\section{Acknowledgments}

This research was supported in part by a grant from the National Institute of Mental Health (Torres, R21 MH077735).

\section{Footnotes}

Some of these data were presented at the meeting of the National Multicultural Conference and Summit, January 2011, in Seattle, Washington.

${ }^{1}$ To test whether the hypothesized mediational paths differed by gender, separate analyses of the multiple mediator model were conducted for men and women. Compared to the full sample, results were unchanged for women but for men only the direct and total effects of acculturative stress on depression were significant. Given that the sample was comprised of nearly twice as many women as men, nonsignificant gender results may reflect limited statistical power. Results are available from the first author (M.W.D.) on request.

\section{Contributor Information}

Mark W. Driscoll, Psychology Department, Marquette University.

Lucas Torres, Psychology Department, Marquette University.

\section{References}

Abraido-Lanza AF, Vásquez E, Echeverría SE. En las manos de Dios [in God's hands]: Religious and other forms of coping among Latinos with Arthritis. Journal of Consulting and Clinical Psychology. 2004;72:91-102.

Alegría M, Canino G, Shrout PE, Woo M, Duan N, Vila M, et al. Prevalence of mental illness in immigrant and non-immigrant U.S. Latino groups. American Journal of Psychiatry. 2008;165:359-369.

Cultural Diversity and Ethnic Minority Psychology, Vol 19, No. 4 (October 2013): pg. 373-382. DOI. This article is (C) American Psychological Association and permission has been granted for this version to appear in e-

Publications@Marquette. American Psychological Association does not grant permission for this article to be further copied/distributed or hosted elsewhere without the express permission from American Psychological Association. 
Alegría M, Mulvaney-Day N, Torres M, Polo A, Cao Z, Canino G. Prevalence of psychiatric disorders across Latino subgroups in the United States. American Journal of Public Health. 2007;97:68-75.

Balls Organista $\mathrm{P}$, Organista KC, Kursasaki K. The relationship between acculturation and ethnic minority mental health. In: Chun KM, Balls Organista P, Marín G, editors. Acculturation: Advances in theory, measurement, and applied research. Washington, DC: American Psychological Association; 2003. pp. 139-161.

Bandura A. Self-efficacy: Toward a unifying theory of behavioral change. Psychological Review. 1977;84:191-215.

Bandura A. Social cognitive theory: An agentic perspective. Annual Review of Psychology. 2001;52:1-26.

Baron RM, Kenny DA. The moderator-mediator variable distinction in social psychological research: Conceptual, strategic, and statistical considerations. Journal of Personality and Social Psychology. 1986;51:1173-1182.

Benet-Martínez V, Leu J, Lee F, Morris MW. Negotiating biculturalism: Cultural frame switching in biculturals with oppositional versus compatible cultural identities. Journal of Cross-Cultural Psychology. 2002;33:492-516.

Berry JW. Acculturative stress. In: Wong PTP, Wong LCJ, editors. Handbook of multicultural perspectives on stress and coping. New York, NY: Springer; 2006. pp. 287-298.

Bolger N, Zuckerman A. A framework for studying personality in the stress process. Journal of Personality and Social Psychology. 1995;69:890-902.

Castillo LG, Cano MG, Chen SW, Blucker RT, Olds TS. Family conflict and intragroup marginalization as predictors of acculturative stress in Latino college students. International Journal of Stress Management. 2008;15:43-52.

Cultural Diversity and Ethnic Minority Psychology, Vol 19, No. 4 (October 2013): pg. 373-382. DOI. This article is (C) American Psychological Association and permission has been granted for this version to appear in e- 
Chun C, Moos RH, Cronkite RC. Culture: A fundamental context for the stress and coping paradigm. In: Wong PTP, Wong LC], editors. Handbook of multicultural perspectives on stress and coping. New York, NY: Springer; 2006. pp. 29-53.

Constantine MG, Okazaki S, Utsey SO. Self-concealment, social selfefficacy, acculturative stress, and depression in African, Asian, and Latin American international college students. American Journal of Orthopsychiatry. 2004;74:230-241.

Crockett L], Iturbide MI, Torres Stone RA, McGinley M, Rafaelli M, Carlo G. Acculturative stress, social support, and coping: Relations to psychological adjustment among Mexican American college students. Cultural Diversity and Ethnic Minority Psychology. 2007;13:347-355.

Dawson BA, Panchanadeswaran S. Discrimination and acculturative stress among first-generation Dominicans. Hispanic Journal of Behavioral Sciences. 2010;32:216-231.

Finch BK, Kolody B, Vega WA. Perceived discrimination and depression among Mexican-origin adults in California. Journal of Health and Social Behavior. 2000;41:295-313.

Finch BK, Hummer RA, Kolody B, Vega WA. The role of discrimination and acculturative stress in the physical health of Mexican-origin adults. Hispanic Journal of Behavioral Sciences. 2001;23:399429.

Garcia Coll C, Akerman A, Cicchetti D. Cultural influences on developmental processes and outcomes: Implications for the study of development and psychopathology. Development and Psychopathology. 2000;12:333-356.

Grzywacz JG, Hovey JD, Seligman LD, Arcury TA, Quandt SA. Evaluating the short-form versions of the CES-D for measuring depressive symptoms among immigrants from Mexico. Hispanic Journal of Behavioral Sciences. 2006;28:404-424.

Cultural Diversity and Ethnic Minority Psychology, Vol 19, No. 4 (October 2013): pg. 373-382. DOI. This article is (c) American Psychological Association and permission has been granted for this version to appear in e- 
NOT THE PUBLISHED VERSION; this is the author's final, peer-reviewed manuscript. The published version may be accessed by following the link in the citation at the bottom of the page.

Grzywacz JG, Quandt SA, Chen H, Isom S, Kiang L, Vallejos Q, et al. Depressive symptoms among Latino farmworkers across the agricultural season: Structural and situational influences. Cultural Diversity and Ethnic Minority Psychology. 2010;16:335343.

Hovey JD. Acculturative stress, depression, and suicidal ideation in Mexican immigrants. Cultural Diversity and Ethnic Minority Psychology. 2000;6:134-151.

Hovey JD, Magaña C. Acculturative stress, anxiety, and depression among Mexican immigrant farmworkers in the Midwest United States. Journal of Immigrant Health. $2000 ; 2: 119-131$.

Kanter JW, Santiago-Rivera AL, Rusch LC, Busch AM, West P. Initial outcomes of a culturally adapted behavioral activation for Latinas diagnosed with depression at a community clinic. Behavior Modification. 2010;34:120-144.

Kohout FJ, Berkman LF, Evans DA, Cornoni-Huntley J. Two shorter forms of the CES-D depression symptoms index. Journal of Aging and Health. 1993;5:179-193.

Lazarus RS, Folkman S. Stress, Appraisal, and Coping. New York: Springer-Verlag; 1984.

Lee DL, Ahn S. Discrimination against Latina/os: A meta-analysis of individual-level resources and outcomes. The Counseling Psychologist. 2012;40:28-65.

Locke TF, Newcomb MD, Duclos A, Goodyear RK. Psychosocial predictors and correlates of dysphoria in adolescent and young adult Latinas. Journal of Community Psychology. 2007;35:135149.

Markus HR, Kitayama S. Culture and the self: Implications for cognition, emotion, and motivation. Psychological Review. $1991 ; 98: 224-253$.

Cultural Diversity and Ethnic Minority Psychology, Vol 19, No. 4 (October 2013): pg. 373-382. DOI. This article is (c) American Psychological Association and permission has been granted for this version to appear in ePublications@Marquette. American Psychological Association does not grant permission for this article to be further copied/distributed or hosted elsewhere without the express permission from American Psychological Association. 
NOT THE PUBLISHED VERSION; this is the author's final, peer-reviewed manuscript. The published version may be accessed by following the link in the citation at the bottom of the page.

Mendelson T, Rehkopf DH, Kubzansky LD. Depression among Latinos in the United States: A meta-analytic review. Journal of Consulting and Clinical Psychology. 2008;76:355-366.

Ogbu JU. Origins of human competence: A cultural-ecological perspective. Child Development. 1981;52:413-429.

Oyserman D, Coon HM, Kemmelmeier M. Rethinking individualism and collectivism: Evaluation of theoretical assumptions and metaanalysis. Psychological Bulletin. 2002;128:3-72.

Pérez DJ, Fortuna L, Alegría M. Prevalence and correlates of everyday discrimination among U.S. Latinos. Journal of Community Psychology. 2008;36:421-433.

Pew Hispanic Center. Statistical portrait of Hispanics in the United States, 2010. 2012 Retrieved from http://www.pewhispanic.org/files/2012/02/Statistical-Portraitof-Hispanics-in-the-United-States-2010 Apr-3.pdf.

Preacher KJ, Hayes AF. Asymptotic and resampling strategies for assessing and comparing indirect effects in multiple mediator models. Behavior Research Methods. 2008;40:879-891.

Radloff LS. The CES-D Scale: A self-report depression scale for research in the general population. Applied Psychological Measurement. 1977;1:385-401.

Rodriguez N, Myers HF, Mira CB, Flores T, Garcia-Hernandez L. Development of the Multidimensional Acculturative Stress Inventory for adults of Mexican origin. Psychological Assessment. 2002;14:451-461.

Scholz U, Doña BG, Sud S, Schwarzer R. Is general self-efficacy a universal construct? Psychometric findings from 25 countries. European Journal of Psychological Assessment. 2002;18:242251.

Cultural Diversity and Ethnic Minority Psychology, Vol 19, No. 4 (October 2013): pg. 373-382. DOI. This article is (C) American Psychological Association and permission has been granted for this version to appear in ePublications@Marquette. American Psychological Association does not grant permission for this article to be further copied/distributed or hosted elsewhere without the express permission from American Psychological Association. 
Schwartz SJ, Zamboanga BL. Testing Berry's model of acculturation: A confirmatory latent class approach. Cultural Diversity and Ethnic Minority Psychology. 2008;14:275-285.

Schwarzer R, Jerusalem M. Generalized Self-Efficacy Scale. In: Weinman J, Wright $S$, Johnson $M$, editors. Measures in health psychology: A user's portfolio, causal and control beliefs. Windsor, England: Nfer-Nelson; 1995. pp. 35-37.

Shrout PE, Bolger N. Mediation in experimental and nonexperimental studies: New procedures and recommendations. Psychological Methods. 2002;7:422-445.

Torres L. Attributions to discrimination and depression among Latino/as: The mediating role of competence. American Journal of Orthopsychiatry. 2009;79:118-124.

Torres L. Predicting levels of Latino depression: Acculturation, acculturative stress, and coping. Cultural Diversity and Ethnic Minority Psychology. 2010;16:256-263.

Torres L, Driscoll MW, Burrow AL. Racial microaggressions and psychological functioning among highly achieving AfricanAmericans: A mixed-methods approach. Journal of Social and Clinical Psychology. 2010;29:1074-1099.

Torres L, Driscoll MW, Voell M. Discrimination, acculturation, acculturative stress, and Latino psychological distress: A moderated mediational model. Cultural Diversity and Ethnic Minority Psychology. 2012;18:17-25.

Torres $L$, Ong AD. A daily diary investigation of Latino ethnic identity, discrimination, and depression. Cultural Diversity and Ethnic Minority Psychology. 2010;16:561-568.

Umaña-Taylor A, Alfaro EC. Acculturative stress and adaptation. In: Villarruel FA, Carlo G, Grau JM, Azmitia M, Cabrera NJ, Chahin TK, editors. Handbook of U.S. Latino psychology: Developmental and community-based perspectives. Los Angeles, CA: SAGE Publications; 2009. pp. 135-152.

Cultural Diversity and Ethnic Minority Psychology, Vol 19, No. 4 (October 2013): pg. 373-382. DOI. This article is (C) American Psychological Association and permission has been granted for this version to appear in ePublications@Marquette. American Psychological Association does not grant permission for this article to be further copied/distributed or hosted elsewhere without the express permission from American Psychological Association. 
NOT THE PUBLISHED VERSION; this is the author's final, peer-reviewed manuscript. The published version may be accessed by following the link in the citation at the bottom of the page.

Umaña-Taylor AJ, Updegraff KA, Gonzales-Backen MA. Mexican-origin adolescent mothers' stressors and psychosocial functioning: Examining ethnic identity affirmation and familism as moderators. Journal of Youth and Adolescence. 2011;40:140157.

U.S. Census Bureau. 2010 American Community Survey one-year estimates: Household income in the past 12 months (in 2010 inflation-adjusted dollars) (Hispanic or Latino householder) 2010 Retrieved from http://factfinder2.census.gov/faces/nav/jsf/pages/index.xhtml.

U.S. Census Bureau. 2010 American Community Survey one-year estimates: ACS demographic and housing estimates. 2010 Retrieved from http://factfinder2.census.gov/faces/tableservices/jsf/pages/prod uctview.xhtml?fpt=table.

Yeh CJ, Kwong Arora A, Wu KA. A new theoretical model of collectivistic coping. In: Wong PTP, Wong Wong LC], editors. Handbook of multicultural perspectives on stress and coping. New York, NY: Springer; 2006. pp. 55-72.

Zea MC, Belgrave FC, Townsend TG, Jamara SL, Banks SR. The influence of social support and active coping on depression among African Americans and Latinos with disabilities. Rehabilitation Psychology. 1996;41:225-242.

Zea MC, Reisen CA, Tyler FB. Reliability, ethnic comparability, and validity evidence for a condensed measure of proactive coping: The BAPC-C. Educational and Psychological Measurement. $1996 ; 56: 330-343$.

Cultural Diversity and Ethnic Minority Psychology, Vol 19, No. 4 (October 2013): pg. 373-382. DOI. This article is (C) American Psychological Association and permission has been granted for this version to appear in ePublications@Marquette. American Psychological Association does not grant permission for this article to be further copied/distributed or hosted elsewhere without the express permission from American Psychological Association. 